\title{
The Influence of Religiosity and Risk Taking on Cybersex Engagement among Postgraduate Students: A Study in Malaysian Universities
}

\author{
Soudabeh Ghoroghi, Siti Aishah Hassan, and Ahmad Fauzi Mohd Ayub
}

\begin{abstract}
This study attempts to develop a predictive model to enhance the understanding of cybersex by testing hypotheses on the relationships between religiosity, risk taking, and cybersex engagement. Using multistage proportional sampling, 256 postgraduate students who completed an online survey sent to their email addresses were randomly selected from five Malaysian universities. Results provided support for the proposed theoretical model by explaining $22 \%$ of variance in endogenous variable. Statistically significant negative relationship was found to exist between religiosity and cybersex engagement. The study also demonstrated a positive significant relationship between risk taking and cybersex engagement. University counselors would do well to be aware, and develop accurate and general knowledge about online sexual activities, address and prevent the probability of it becoming an addiction with serious life consequences for students.
\end{abstract}

Index Terms-Cybersex, high order reflective construct, postgraduate students, religiosity.

\section{INTRODUCTION}

Technological progress of the Internet has led to the emergence and rapid growth of adult entertainment such as the delivery of sexual materials ranging from text, stories, to pictures, and videos. Statistics related to Internet sexuality have pointed out that about $42.7 \%$ of Internet users visit pornographic web sites [1].

In the present study, "Cybersex" is simply defined as "The use of the Internet for sex" [2], and comprises engagement in diverse sexually motivated behaviors in interactive or solitary form including: viewing text, pictures, videos, sexchats, using webcam, specific information search about sexual issues, establishing sexually-biased contacts online, etc. [3]-[5]. These activities can be grouped into solitary-arousal (e.g. watching and downloading pornography), partnered-arousal or interactive, (e.g. sex chats, webcamming, sharing sexual fantasies), and non-arousal activities (e.g. directed information search) [5], [6].

Several studies conclude that cybersex can alter the user's

Manuscript received July 25, 2016; revised October 21, 2016.

S. Gh and Siti Aishah Hassan are with the Department of Counselor Education and Counseling Psychology, Faculty of Educational Studies, Universiti Putra Malaysia, Malaysia (e-mail: sudygh@yahoo.com, siti_aishahh@upm.edu.my).

Ahmad Fauzi Mohd Ayub is with Department of Foundation Studies, Faculty of Educational Studies, Universiti Putra Malaysia, Malaysia (e-mail afmy@upm.edu.my). mental, emotional, and social characteristics. While it is true that most Internet users use it for recreational or utilitarian purposes, there are individuals who develop an addiction to cybersex [7]. Cybersex addiction is defined as a compulsion accompanied by extreme Internet sexually-oriented behavioral patterns that prevail over an individual's life, thoughts, and feelings [8].

Students, especially university students, spent more time online and are in centre attention of researchers because of their potential ability to engage in compulsive Internet behaviors. Undoubtedly, students are vulnerable in the face of problems related to Internet use, especially to excessive Internet use. Malaysia's level of social networking activity has shown an exceptionally high level of engagement. In 2010, Malaysia was number nine in the world and in terms of the number of Facebook users, the country is ranked third highest in the Asia Pacific region [9]. Pornography and other forms of online sexual activities are known to be rampant as reported in the media [10] and especially among university students in Malaysia [11].

It is stated that influential factors such as personal characteristics have been a comparatively neglected area of research in the field of cybersexual studies [12]. Therefore, exploring the possibility that students with certain personal characteristics are more likely to be excessive cybersex users might help us to better predict and intervene prior to the development of addictive behaviors. In view of that, students' risk taking propensity, and religiosity is highlighted as possible influencers in cybersex engagement.

\section{LITERATURE REVIEW}

\section{A. Religiosity}

For a long time now, psychologists have shown great interest, with varying degrees of favor or disfavor, in the role that religion plays in interpreting and responding to life events and psychological adjustment [13]. However, there has been little attention paid to the relationship between technology adoption and religion and the tension between technological development and religious beliefs [14]. The study of religion and the Internet, which is a subfield of Internet Studies can improve our knowledge and discussion of the larger social and cultural shifts at work within networked society [15].

Malaysia is an excellent example of a multiethnic and multi-religious country in Southeast Asia with a relatively positive level of cultural and religious tolerance [16]. Ethnic Malays and Bumiputeras comprise $78 \%$ of the total population of about 30 million [17], and almost all of them are 
Sunni Muslims and follow the Shafi'i legal school of Islam [18]. Huff [19] maintains that the experience of Malaysia, with its Muslim majority population and rapid endorsement of technology, provides a strong contrast to Muslim nations in the Middle East, where political sensitivities have impeded the development of information technology [19].

According to Campbell [20] the rise of religious fundamentalism globally within traditional religions such as Islam, Judaism, and Christianity, reveals reactions to globalization and technology. However, various religious communities have adopted and in some cases embraced the Internet as part of their contemporary religious mission and strategy for growth [21].

This contention was echoed by a study on a sample of 2,698 Turkish Muslims by Hesapçı Sanaktekın Aslanbay, and Gorgulu [14]. The result of the study shows that the degree of religiosity significantly affected the patterns of Internet consumption. High believers, compared to moderate or non-believer groups, use the Internet more for the purpose of searching for information [14]. Policy-wise, there is a relationship between religious belief and advocating greater restriction on access to Internet pornography [22]. Religious individuals tend to disapprove of pornography use and support pornography censorship [23]. In some related studies, it was found that pornography use was lower in religious populations than non-religious and secular populations [24], [25].

In contrast, the results from two studies of undergraduate samples (Study1, N=331; Study2, N=97) of Grubbs et al. [26] showed that religiosity and perceived addiction to pornography were strongly and positively related and that this relationship was mediated by moral disapproval of pornography use. These results persisted even when actual use of pornography was controlled.

\section{B. Risk Taking}

As a personality characteristic or trait, risk-taking propensity is a form of individual difference [27], and can be identified by a natural tendency to the seeking of varied, novel, complex and intense experiences and engaging in potentially harmful behaviors [28].

In recent years, there have been growing concerns about risk-taking behaviors by students. In early studies, the prevalence of adolescent risk-taking behaviors has been addressed through numerous epidemiological surveys. These studies have repeatedly focused, almost exclusively, on behaviors, including such activities as driving a car after drinking, riding with a drunk driver, shoplifting, having sex without a condom, etc. [29]. Nowadays, the spread of risky behaviors in society make social scientists continue to devote considerable attention to spillover effects from risky behaviors especially among college and university students [30].

Risk taking is part of life, but people differ in their risk-taking propensity. Some people enjoy risky pursuits while others dislike such activities [31]. It is very important to see association between risk taking behaviors and cybersex involvement because risk taking online can translate into actual risky sexual encounters.

Several survey results suggest that more frequent engagement in cybersex has been positively associated with risky behaviors. Users feel safe using the Internet for sexual purposes, encouraging more adventurous and riskier behaviors [32], [33].

In accordance with the mentioned arguments we proposed the following hypotheses:

H1. Religiosity negatively influences cybersex engagement.

H2. Risk taking positively influences cybersex engagement.

\section{METHOD}

We conducted a quantitative online survey among 256 master's and PhD. students. Due to the sensitivity of the research topic, before recruiting participants for the study, ethical approval for this study was granted by the Ethics Committee for Research Involving Human Subjects Universiti Putra Malaysia (JKEUPM). Further, prior to answering the survey questions, an electronic consent form was used as a tool to provide assurance to participants that their privacy, confidentiality, and participation would be fully anonymous with no link to their email address. The consent form further assured that their participation was voluntary and withdrawal would have no consequences. Sample size when conducting PLS path modeling adheres to guidelines from Chin [34] that suggested a minimum sample size equal to or exceeding 10 times the larger of the largest number of structural paths leading to a latent variable. In this study the largest number of structural paths belongs to religiosity scale (LPCG dimension) with 8 indicators. Therefore, a sample comprising 256 respondents who completed questionnaires was acceptable. This study uses multistage proportional sampling. First, five universities were randomly selected among Klang Valley universities (the states of Selangor and Kuala Lumpur) including two public and three private universities. Second, proportional sampling was applied to come up with appropriate sample sizes for each university. In the third stage, having students email addresses, there was the possibility for random selection of emails in each university based on proportional sample size in the second stage. Considering the issues of confidentiality, selected universities are called A, B, C, D, and E.

\section{A. Instrumentation}

The study applied three instruments to measure the variables of the study. These include an online questionnaire containing questions about respondents' age, gender, study level, sexual orientation as well as the following questionnaires:

Internet Sex Screening Test (ISST) Delmonico and Miller [35]: Among the instruments, it is an excellent measure for evaluating online sexual behaviors [36], [37]. The rating ISST scale administered is a 25 -item, True-False measure of online sexual behavior developed by Delmonico [38]. ISST has been utilized as a self-administered, screening instrument to assist individuals in determining whether their Internet sexual behavior has reached the stage of being clinically problematic. Delmonico and Miller [35] used factor analysis to empirically establish sub-scales, of which there are five: (a) online sexual 
compulsivity (OSC), (b) online sexual behavior-social (OSB-S), (c) online sexual behavior-isolated (OSB-I), (d) online sexual spending (OSS), and (e) interest in online sexual behavior (IOSB). ISST produces a total score evaluating problematic online sexual behavior as well as the scores of the five subscales. Sample items of ISST are: "I have a sexualized username or nickname that I use on the Internet", "I have made promises to myself to stop using the Internet for sexual purposes," and "I have stayed up after midnight to access sexual material online". For this study, the scale was transformed into a 5-point Likert scale. The ISST has proof of convergent validity, and has a relation with another measure of sexual addiction and internal consistency for sub-scales in the study reported as $\alpha=0.51$ to 0.86 [35]. The present study resulted in $\alpha=0.64$ to 0.83 .

Domain-Specific Risk-Taking Scale (DOSPERT) Blais and Weber [39]: Risk taking is often domain specific, meaning that somebody's ethical risk taking may not predict his or her health or social risk taking [39]. The risk-taking responses of the 18-item version of the DOSPERT Scale assess behavioral intentions or how likely it is that respondents might participate in risky activities/behavior developed by Blais and Weber [39]. The risk-taking scale assesses behavioral tendencies, and risky behaviors derived from five domains of life (ethical, financial, health/safety, social, and recreational risks) on a 30 -item scale. This study however uses only the ethical, health/safety and social domains. Sample items use a 7-point rating scale ranging from 1 (extremely unlikely) to 7 (extremely likely), and include "Revealing a friend's secret to someone else" and "Engaging in unprotected sex". Blais and Weber [39] provided evidence proof of the factorial and convergent/discriminant validity of the scores regarding constructs such as sensation seeking, dispositional risk taking, intolerance for ambiguity, and social desirability. Construct validity was also gauged using correlations with the findings of a risky gambling task and also through testing gender differences. Hanoch, Johnson, and Wilke [40] have also provided proof of the DOSPERT Scale's construct validity by using it to illustrate that those chosen to show high levels of risk taking in one content area can be risk averse in other risky domains. The DOSPERT scale has been observed to possess high internal consistency (Cronbach's $\alpha=0.71-0.86$ ) and moderate test-retest reliability estimates [39]. Results of the study by Buelow and Brunell [41] showed moderate to high Internal consistency $(\alpha=0.65-0.89)$ for the scale. The present study resulted in $\alpha=0.70$ to 0.79 .

Strength of Religious Faith Questionnaire (SRFQ): Respondents' conviction of religious faith is assessed using the instrument adapted and rewritten using the following religiosity questionnaires:

a) Muslim Religiosity-Personality Inventory (MRPI) [42], b) Hoge's Intrinsic Religiosity Scale (IRS) [43] and c) Age Universal I/E-Revised Scale (I/E-R) [44].

The instrument has 12 items on a 5-point scale ranging from 1 (strongly disagree) to 5 (strongly agree), with three items being reverse-scored. Higher scores are indication of higher levels of religiosity. Because the instrument does not contain references to any specific religious orientation, it may be utilized with students of all religious affiliations as well as for those without any interest in or affiliation with religious traditions and perspectives. Sample of items includes: "In my life, I experience the presence of the Divine (i.e., God)" and "I try to understand the meaning of religious words/verses". Since SRFQ was adapted to fit the study, factor analysis was developed for the newly-adapted SRFQ for the purpose of determining the number of distinct constructs required to explain the pattern of correlations among a set of measures [45]. The constructs identified are: Level of people's consciousness of God (LPCG) and Faith-based religious values (FBRV). For the process of validating the newly adapted Strength of Religious Faith Questionnaire (SRFQ) instrument, and to prove the validity, after revision, rewording, and approval for completeness by the first expert, copies of the scale were given to three other experts. They studied and certified that the scale was good enough to measure what it intended to measure. The feedback received from the expert review panel was used to revise, re-word, and improve the content of the adapted survey instrument. The present study resulted in $\alpha=0.80$ to 0.93 .

\section{B. Statistical Tools}

The research hypotheses have been tested using partial least squares-structural equation modeling (PLS-SEM) to assess both the measurement and structural models. This study uses SmartPLS 3.0 [46]. The use of PLS is justified for the following reasons: 1) research objective would be prediction of the dependent variables rather than confirmation of structural relationships; 2) this study uses latent variable scores as indicators of the second-order construct 3) data in this study exhibit skewness and non-normality that is not an issue when the study uses PLS [47]-[49]. All variables used in the study are reflective. Reflective indicators are seen as functions of the latent construct, and changes in the latent construct are expressed in the changes in the indicator (manifest) variables [50].

In line with what has been suggested by Becker, Klein, and Wetzels [51] and Hair, Ringle, and Sarstedt [52], and having the multi-dimensional reflective-reflective constructs, a two-stage approach was used in the study. The construct scores of the first-order constructs will be estimated in a first-stage model in the absence of the second-order construct. The model subsequently utilizes these first-stage construct scores to indicate the higher order latent variable in a separate second-stage analysis [51].

\section{ANALYSIS AND FINDINGS}

\section{A. Descriptive Analysis}

Participants ranged in age from 22 to 51 years $(M=30.84$, $\mathrm{SD}=6.23$ ). Table I summarizes the demographic profile of respondents. Gender was relatively evenly distributed and the sample included $130(50.8 \%)$ males, while their female counterparts comprised $48.8 \%(n=125)$. Only a single student introduced himself as transgender. A total of 129 (50.4\%) of them were master and 127 (49.6\%) PhD students. The majority (226) of participants were heterosexual (88.3\%), $16(6.3 \%)$ bisexual, and $10(3.9 \%)$ were uncertain about their 
sexual orientation. Only $4(1.6 \%)$ respondents indicated that members of the same sex. they were homosexual and were sexually attracted to

TABLE I: DEMOGRAPHIC PROFILE OF RESPONDENT

\begin{tabular}{|c|c|c|c|c|}
\hline \multirow{2}{*}{ Study level } & Master & PhD & & \\
\cline { 2 - 5 } & 129 & 127 & & \\
\hline \multirow{2}{*}{ Percentage \% } & 50.4 & 49.6 & & \\
\hline \multirow{2}{*}{ Gender } & Male & Female & Transgender & \\
\cline { 2 - 5 } & 130 & 125 & 1 & Homosexual \\
\hline Percentage \% & 50.8 & 48.8 & Uncertain & 4 \\
\hline \multirow{2}{*}{ Sexual orientation } & Heterosexual & Bisexual & 10 & 1.6 \\
\cline { 2 - 5 } & 226 & 16 & 3.9 & \\
\hline \multirow{2}{*}{ Percentage \% } & 88.3 & 6.3 & & \\
\hline
\end{tabular}

\section{B. Assessment of the Model Using PLS-SEM}

The assessment of a model in PLS-SEM requires a two-step process that involves measuring the outer/measurement and inner/structural model [53]-[55]. The initial step in PLS analysis is to analyze the measurement model to measure loading of indicators (specific questions) on the theoretically defined constructs. The structural model assesses the relationships between the constructs through path analysis [53], [54].

\section{Measurement Model}

To assess the measurement model a two-step analysis was conducted. Initially, the first-order factors were analyzed for all constructs. According to Chin [53], and Hair et al. [54], to define the reliability and validity of the reflective measurement, the Composite Reliability (CR) and Average Variance Extracted (AVE) were used.

To establish reliability of the reflective measurement model, indicator reliability and construct reliability were assessed. In assessing a model's indicator reliability, the loading of each indicator must be higher than 0.7 to be considered acceptable [54]. A loading lower than 0.4 indicates that an item should be considered for removal, and items with a loading of 0.4-0.7 should be considered for removal if their removal increases the CRs and AVEs above the threshold [53], [47].

Internal consistency reliability was established (Table II) because:

1) All the Cronbach's alpha values for the constructs were between 0.62 and 0.96 showing reliability of the measures or survey instrument.

2) Composite reliabilities $(\mathrm{CR} s)$ exceeded 0.8 , suggesting that the scale items for the constructs are reliable.

Indicator reliability and convergence validity were established because:

3) Examining the loadings for 10 constructs, 40 of the items had loadings of 0.56 to 0.92 . Items listed in Table III were removed to raise the AVEs and CRs achieved acceptable convergent validity [47], [53].
All AVEs values were greater than 0.5 and considered acceptable except items reported in Table III.

Discriminant validity of the latent variables was established:

1) Using the Heterotrait-Monotrait Ratio (HTMT), variables showed acceptable discriminant validity (HTMT of below 0.85) according to the $\mathrm{HTMT}_{.85}$ criterion [56] (Table IV);

2) Using the Fornell and Larcker criterion:

The AVE of each latent construct was higher than the construct's highest squared correlation with any other latent construct [53], [57]. See Table V. Moreover, all loadings were high and cross-loadings were low in comparison with the loadings [53], [54], [58].

Table VI shows the results of the assessment of religiosity, risk taking, and cybersex as second order reflective constructs.

The results presented in Tables VI and VIII indicate that the reliability, convergent validity, and discriminant validity for the three second order constructs met acceptability criteria.

\section{Structural Model}

Two criteria should be considered and interpreted in using PLS-SEM: the path coefficients and the R2 measure for the endogenous constructs [53], [54]. Structural model assessment determines some results such as the variance explanation of endogenous constructs, effect sizes, and predictive relevance [49]. In accordance with Hair et al. [2014) the study takes 5,000 resamples to determine statistical significance.

Before looking at the results of the path model, Standardized Root Mean Square Residual (SRMR) criterion should be reported for model validation purposes [59]. In this study SRMR is 0.058 (below cut-off of 0.08) indicating a satisfying overall goodness of model fit.

Using PLS algorithm R2 measure was calculated for the endogenous latent variable cybersex engagement to measure the model's predictive accuracy (Fig. 1). R2 values of 0.67 , 0.33 , and 0.19 are considered substantial, moderate, and weak respectively by Chin [53]. R2 measure was 0.22 for cybersex engagement. $\mathrm{R} 2=0.220$ is considered relatively high by 
behavioral research [47], [57]. To avoid bias toward adjusted R2 needs to be calculated. R2adj for cybersex was complex models, Hair et al. [47] suggest the criterion 0.214 .

$\mathrm{T}$

ABLE II: RESUlTS OF ASSESSMENT OF MEASUREMENT MODEL FOR FIRST ORDER CONSTRUCTS

\begin{tabular}{|c|c|c|c|c|c|}
\hline Construct & Item & $\begin{array}{c}\text { Factor } \\
\text { Loading }\end{array}$ & $\mathrm{CR}$ & $\begin{array}{c}\text { Cronbach's } \\
\text { alpha }\end{array}$ & AVE \\
\hline \multirow{9}{*}{ Religiosity-LPCG } & & & 0.968 & 0.962 & 0.789 \\
\hline & REL11 & 0.865 & & & \\
\hline & REL12 & 0.921 & & & \\
\hline & REL13 & 0.920 & & & \\
\hline & REL14 & 0.917 & & & \\
\hline & REL15 & 0.858 & & & \\
\hline & REL16 & 0.887 & & & \\
\hline & REL17 & 0.864 & & & \\
\hline & REL18 & 0.871 & & & \\
\hline \multirow{5}{*}{ Religiosity-FBRV } & & & 0.949 & 0.928 & 0.823 \\
\hline & REL21 & 0.934 & & & \\
\hline & REL22 & 0.916 & & & \\
\hline & REL23 & 0.899 & & & \\
\hline & REL24 & 0.878 & & & \\
\hline \multirow{6}{*}{ RISK Social } & & & 0.849 & 0.786 & 0.492 \\
\hline & RISK-S1 & 0.763 & & & \\
\hline & RISK-S2 & 0.560 & & & \\
\hline & RISK-S4 & 0.711 & & & \\
\hline & RISK-S5 & 0.866 & & & \\
\hline & RISK-S6 & 0.759 & & & \\
\hline \multirow{4}{*}{ RISK Health/Safety } & & & 0.775 & 0.652 & 0.371 \\
\hline & RISK-HS2 & 0.700 & & & \\
\hline & RISK-HS3 & 0.634 & & & \\
\hline & RISK HS6 & 0.664 & & & \\
\hline \multirow{4}{*}{ RISK Ethical } & & & 0.792 & 0.683 & 0.392 \\
\hline & RISK-E2 & 0.624 & & & \\
\hline & RISK-E3 & 0.705 & & & \\
\hline & RISK-E6 & 0.728 & & & \\
\hline \multirow{3}{*}{ Cybersex - IOSB } & & & 0.863 & 0.685 & 0.760 \\
\hline & IOSB1 & 0.852 & & & \\
\hline & IOSB2 & 0.891 & & & \\
\hline \multirow{4}{*}{ Cybersex - OSS } & & & 0.792 & 0.617 & 0.560 \\
\hline & OSS1 & 0.772 & & & \\
\hline & OSS2 & 0.719 & & & \\
\hline & OSS3 & 0.752 & & & \\
\hline \multirow{5}{*}{ Cybersex - OSB-S } & & & 0.831 & 0.749 & 0.497 \\
\hline & OSB-S1 & 0.758 & & & \\
\hline & OSB-S3 & 0.670 & & & \\
\hline & OSB-S4 & 0.693 & & & \\
\hline & OSB-S5 & 0.743 & & & \\
\hline \multirow{5}{*}{ Cybersex- OSB-I } & & & 0.878 & 0.815 & 0.644 \\
\hline & OSB-I1 & 0.759 & & & \\
\hline & OSB-I2 & 0.820 & & & \\
\hline & OSB-I3 & 0.796 & & & \\
\hline & OSB-I4 & 0.832 & & & \\
\hline \multirow{2}{*}{ Cybersex- OSC } & & & 0.829 & 0.753 & 0.449 \\
\hline & OSC1 & 0.745 & & & \\
\hline
\end{tabular}




\begin{tabular}{|c|c|c|c|c|c|}
\hline \multirow{2}{*}{ Construct } & Item & $\begin{array}{c}\text { Factor } \\
\text { Loading }\end{array}$ & CR & $\begin{array}{c}\text { Cronbach's } \\
\text { alpha }\end{array}$ & AVE \\
\hline \multirow{3}{*}{} & OSC3 & 0.716 & & & \\
\cline { 2 - 3 } & OSC4 4 & 0.667 & & & \\
\cline { 2 - 3 } & OSC6 & 0.724 & & & \\
\hline
\end{tabular}

Using one-tailed $\mathrm{P}$ values for causal links in the model, path coefficients have been calculated [59]. With regard to the religiosity construct, results show that this variable contributes to a significant negative effect on cybersex engagement $(\beta=-0.224, p=0.001)$ and positive and significant path confirmed for the relation of risk taking and cybersex engagement $(\beta=0.351, \mathrm{p}=<0.01)$.

Using Blindfolding in SmartPLS [49], [52], the cross-validated redundancy measure (Q2) was calculated to be 0.155 , thus giving an acceptable predictive validity of exogenous latent variable which is well above zero, indicating the predictive relevance of the PLS path model.
Values "greater than zero imply that the exogenous constructs have predictive relevance for the endogenous construct under consideration [48].

Finally, the effect size for each path model can be obtained by calculating Cohen's $\mathrm{f} 2$, where $0.02,0.15$, and 0.35 have been suggested as small, moderate, and large effects respectively [60]. The f2 presented in Table IX indicates values of 0.060 and 0.15 , which are considered as small and moderate respectively. Therefore the results show that the effect of risk taking on cybersex engagement was higher than the effect of religiosity on cybersex engagement.

TABLE III: REMOVED INDICATORS FROM THE MEASUREMENT MODEL

\begin{tabular}{|c|c|}
\hline Construct & Removed Items \\
\hline RISK Social & RISK-S3 \\
\hline RISK Health/Safety & RISK-HS1, RISK-HS4, RISK-HS5 \\
\hline RISK Ethical & RISK-E1, RISK-E4, RISK-E5 \\
\hline Cybersex- OSB-S & OSB-S2 \\
\hline Cybersex- OSC & OSC2, OSC5 \\
\hline Cybersex-OTHERES & OTHERS1-5 \\
\hline
\end{tabular}

TABLE IV: DISCRIMINANT VALIDITY ASSESSMENT HETEROTRAIT-MONOTRAIT RATIO (HTMT.85) FOR FIRST ORDER CONSTRUCTS

\begin{tabular}{|c|c|c|c|c|c|c|c|c|c|c|}
\hline & HTMT & 1 & 2 & 3 & 4 & 5 & 6 & 7 & 8 & 9 \\
\hline 1 & Religiosity-LPCG & & & & & & & & & \\
\hline 2 & Religiosity-FBRV & 0.327 & & & & & & & & \\
\hline 3 & RISK Social & 0.223 & 0.128 & & & & & & & \\
\hline 4 & RISK Health/Safety & 0.270 & 0.222 & 0.313 & & & & & & \\
\hline 5 & RISK Ethical & 0.231 & 0.124 & 0.363 & 0.806 & & & & & \\
\hline 6 & Cybersex- IOSB & 0.431 & 0.155 & 0.200 & 0.308 & 0.401 & & & & \\
\hline 7 & Cybersex - OSS & 0.328 & 0.136 & 0.133 & 0.455 & 0.539 & 0.734 & & & \\
\hline 8 & Cybersex - OSB-S & 0.300 & 0.090 & 0.202 & 0.349 & 0.541 & 0.746 & 0.775 & & \\
\hline 9 & Cybersex - OSB-I & 0.347 & 0.071 & 0.174 & 0.298 & 0.381 & 0.686 & 0.728 & 0.768 & \\
\hline 10 & Cybersex - OSC & 0.393 & 0.083 & 0.152 & 0.409 & 0.479 & 0.789 & 0.813 & 0.789 & 0.831 \\
\hline
\end{tabular}




\section{DISCUSSION}

This study was the first of its kind to examine the influence of religiosity and risk taking on engagement in cybersex among university students in Malaysia with analysis done using PLS-SEM.

Although previous studies might not have examined higher order constructs of variables used in this study, in general, the results of the current study are consistent with the findings of previous studies. The result of strong negative effect of religiosity on cybersex engagement is in line with [22], [23]. The result of influence of risk taking on cybersex engagement was consistent with the study of Prause and Finn [32], and Young [33] that found risky behaviors have been positively associated with more frequent engagement in cybersex.

This study used a multi-dimensional scale to assess the relationship between religiosity, risk taking and cybersex engagement. While previous studies have also shown the association of religiosity and online sexual activities [23-26], and risk taking and cybersex [32], [33], few studies have developed an integrated predictive model using higher order constructs. This modeling approach reduces model complexity, achieves theoretical parsimony, and can avoid multicollinearity [47], [61]. Therefore, in summarizing the results of this study, it can be said that the students' religiousness is a protective factor against cybersex engagement and more frequent engagement in cybersex has been positively associated with risk taking propensity.

TABLE V: RESULT OF DISCRIMINANT VALIDITY FOR MODEL (FORNELL AND LARCKER CRITERION) FOR FIRST ORDER CONSTRUCTS

\begin{tabular}{|c|c|c|c|c|c|c|c|c|c|c|c|}
\hline & & 1 & 2 & 3 & 4 & 5 & 6 & 7 & 8 & 9 & 10 \\
\hline & Religiosity-LPCG & 0.888 & & & & & & & & \\
\hline 2 & Religiosity-FBRV & 0.312 & 0.907 & & & & & & & \\
\hline 3 & RISK Social & -0.198 & -0.108 & 0.743 & & & & & & \\
\hline 4 & RISK Health/Safety & -0.151 & -0.149 & 0.256 & 0.729 & & & & & & \\
\hline 5 & RISK Ethical & -0.182 & -0.083 & 0.496 & 0.217 & 0.757 & & & & \\
\hline 6 & Cybersex- IOSB & -0.347 & -0.119 & 0.124 & 0.212 & 0.263 & 0.872 & & & & \\
\hline 7 & Cybersex - OSS & -0.260 & 0.022 & 0.015 & 0.289 & 0.339 & 0.503 & 0.749 & & & \\
\hline 8 & Cybersex - OSB-S & -0.248 & -0.046 & 0.159 & 0.221 & 0.358 & 0.536 & 0.544 & 0.739 & \\
\hline 9 & Cybersex - OSB-I & -0.305 & 0.021 & 0.127 & 0.212 & 0.275 & 0.517 & 0.544 & 0.616 & 0.802 & \\
\hline 10 & Cybersex - OSC & -0.330 & -0.031 & 0.117 & 0.280 & 0.321 & 0.567 & 0.561 & 0.586 & 0.652 & 0.751 \\
\hline
\end{tabular}

NOTE: SQUARE ROOTS OF AVES SHOWN DIAGONALLY IN BOLDFACE

\begin{tabular}{|c|c|c|c|c|}
\hline Construct & Item & Factor Loading & $\mathrm{CR}$ & $\mathrm{AVE}$ \\
\hline \multirow{3}{*}{ Religiosity } & & & 0.741 & 0.610 \\
\hline & LPCG & 0.973 & & \\
\hline & FBRV & 0.522 & & \\
\hline \multirow{4}{*}{ Risk Taking } & & & 0.783 & 0.555 \\
\hline & Social & 0.527 & & \\
\hline & Health/Safety & 0.802 & & \\
\hline & Ethical & 0.863 & & \\
\hline \multirow{6}{*}{ Cybersex } & & & 0.902 & 0.649 \\
\hline & IOSB & 0.773 & & \\
\hline & OSS & 0.771 & & \\
\hline & OSB-S & 0.826 & & \\
\hline & OSB-I & 0.810 & & \\
\hline & OSC & 0.847 & & \\
\hline
\end{tabular}

TABLE VII: DISCRIMINANT VALIDITY ASSESSMENT (FORNELL AND LARCKER CRITERION) FOR SECOND-ORDER CONSTRUCTS

\begin{tabular}{|c|c|c|c|c|}
\hline & & 1 & 2 & 3 \\
\hline 1 & Religiosity & 0.781 & & \\
\hline 2 & RISK & -0.241 & 0.745 & \\
\hline 3 & Cybersex & -0.343 & 0.397 & 0.806 \\
\hline
\end{tabular}


TABLE VIII: RESUlTS OF HETEROTRAIT-MONOTRAIT RATIO (HTMT.85) ANALYSIS FOR SECOND-ORDER CONSTRUCTS

\begin{tabular}{|l|c|c|c|c|}
\hline & HTMT & 1 & \multicolumn{2}{|c|}{2} \\
\hline 1 & Religiosity & & \multicolumn{2}{|c|}{} \\
\hline 2 & RISK & 0.461 & 0.521 & \\
\hline 3 & Cybersex & 0.416 & & \\
\hline
\end{tabular}

TABLE IX: RESULTS OF HYPOTHESIS TESTING

\begin{tabular}{|c|c|c|c|c|c|}
\hline Hypothesis & $\begin{array}{c}\text { Path } \\
\text { coefficient }\end{array}$ & $\begin{array}{c}\mathrm{t} \\
\text { value }\end{array}$ & P value & Effect size & Supported \\
\hline Religiosity $\rightarrow$ Cybersex & -0.224 & 3.051 & 0.001 & 0.059 & Yes \\
\hline Risk taking $\rightarrow$ Cybersex & 0.351 & 4.574 & $<0.01$ & 0.145 & Yes \\
\hline
\end{tabular}

Note: all relationships are calculated one-tallied, statistical significance was set at $5 \%$.

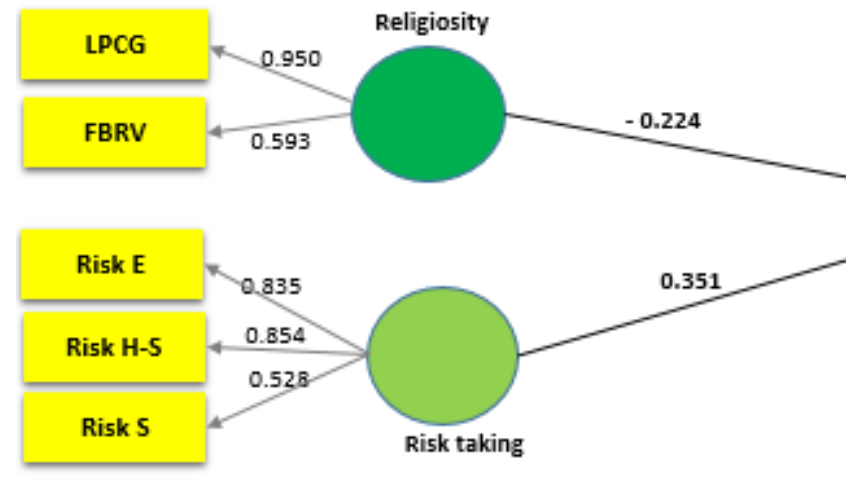

Fig. 1. Assessment of structural model.

\section{IMPLICATIONS AND FUTURE RESEARCH}

In this study, we investigated the effects of factors influencing residents' engagement in cybersex at postgraduate level in selected Malaysian universities. We used a framework to conceptualize the relationships between religiosity, risk taking, and cybersex engagement. However, studies in this regard has been widely criticized in terms of their incompleteness [12], [14]. Therefore, in acknowledging these insufficiencies, we have applied a predictive knowledge-based conceptual framework. This study is a pioneering work in examining variables used in an integrated model using higher order reflective constructs. Furthermore, this study was the first attempt to explore these relationships employing the powerful PLS-SEM statistical method, which is well suited for model development.

The findings of this study also provide and confirm knowledge based on the literature of religiosity and risk taking propensity as individual variations in the likelihood of engaging in cybersex. Indeed, the present study reinforces and highlights the importance of addressing research to examine these variables. The results of this study have some important practical implications for counselors to encourage constructive discussion of the topic in order to minimize its harmful consequences. Considering religiosity was shown to play a significant role against cybersex, belief systems from the students' respective religious traditions can serve in helping them in both prevention and therapy. Notwithstanding, this study is not without its limitations. The present study relied on self-report questionnaires that measure perceptions and intentions of individuals at a single point in time. The fact that perceptions and intentions change over time as individuals gain experience, point to the need for a longitudinal study to validate the findings. Future research may investigate other combinations of individual differences such as psychological triggers of trauma that may potentially mediate the structural relationship in this study.

\section{REFERENCES}

[1] I. Xiao, C. Trestian, and A. Kuzmanovic, "A glance at an overlooked part of the world wide web," presented at the 22nd International Conference on World Wide Web Companion, Rio de Janeiro, Brazil, May 13-17, 2013.

[2] D. D. Rimington, "Examining the perceived benefits for engaging in cybersex behavior among college students," Master dissertation, Utah State Univ, 2008.

[3] N. M. Döring, "The internet's impact on sexuality: A critical review of 15 years of research," Computers in Human Behavior, vol. 25, pp.1089-1101, Sept.2009

[4] M. B. Short, L. Black, A. H. Smith, C. T Wetterneck, and D. E Wells, "A review of Internet pornography use research: Methodology and content from the past 10 years," Cyberpsychology, Behavior, and Social Networking," vol. 15, pp. 13-23, Jan. 2012.

[5] Z. C. Valkyrie, "Cybersexuality in MMORPGs: Virtual sexual revolution untapped," Men and Masculinities, vol.14, pp. 76-96, April 2011.

[6] K. Shaughnessy, S. Byers, and S. J. Thornton, "What is cybersex? Heterosexual students' definitions," International Journal of Sexual Health, vol. 23, pp. 79-89, Jun. 2011.

[7] N. M. Döring, "Internet sexualities," International Handbook of Internet Research, ch. 10, pp. 171-185, 2010.

[8] W. L. Yarber, B. W. Sayad, and B. Strong, Human Sexuality: Diversity in contemporary America, $8^{\text {th }}$ ed. McGraw-Hill, 2013.

[9] N. M Almadhoun, D. Dominic, P. Dhanapal, and L. F. Woon, "Perceived security, privacy, and trust concerns within social networking sites: The role of information sharing and relationships development in the Malaysian higher education institutions' marketing," presented at the IEEE International Conference on Control System, Computing and Engineering, Penang, Malaysia, 426-431, 2011.

[10] W. Y. Low, "Malaysian youth sexuality: Issues and challenges," Journal of the University of Malaya Medical Centre (JUMMEC)," vol. 12, pp. 3-14. Jun.2009.

[11] M. Z. B. Zakaria and D. F. B Baharuddin, "Cybersex addiction treatment: A Malaysian perspective on the needs for counselors' training," presented at the PERKAMA International Conference, Bandung, Indonesia1-15, 2011.

[12] K. Shaughnessy and E. S. Byers, "Contextualizing cybersex experience: Heterosexually identified men and women's desire for and experiences with cybersex with three types of partners," Computers in Human Behavior, vol. 32, pp. 178-185, Mar. 2014.

[13] C. H. Hackney, and G. S. Sanders, "Religiosity and mental health: A meta-analysis of recent studies," Journal for the Scientific Study of Religion, vol. 42, pp. 43-56, Mar. 2003. 
[14] O. Hesapçı Sanaktekın, Y. Aslanbay, and V. Gorgulu, "The effects of religiosity on internet consumption: A study on a Muslim country," Information, Communication \& Society, vol. 16, pp. 1553-1573, Sep. 2012.

[15] H. A. Campbell, "Religion and the internet: A microcosm for studying internet trends and implications," New Media and Society, vol. 15, pp. 680-694, Nov. 2013.

[16] G. K. Brown, "Making ethnic citizens: The politics and practice of education in Malaysia," International Journal of Educational Development, vol. 27, pp. 318-330, May. 2007.

[17] Department of Statistics Malaysia. Population by states and ethnic group. [Online]. Available: http://www.statistics.gov.my/portal/index.php?option=com_content $\&$ view $=$ article $\& i d=471 \&$ lang $=$ en $\&$ Itemid $=0$

[18] Y. A. Momtaz, T. Hamid, R. Ibrahim, N. Yahaya, and S. T. Chai, "Moderating effect of religiosity on the relationship between social isolation and psychological well-being," Mental Health, Religion \& Culture, vol.14, pp. 141-156, Jul. 2010.

[19] T. E. Huff, "Globalization and the internet: Comparing the Middle Eastern and Malaysian experiences," The Middle East Journal, vol.55, pp. 439-458, 2001.

[20] H. A. Campbell, Exploring Religious Community Online: We Are One in the Network, New York: Peter Lang, 2005.

[21] R. Kluver and P. H. Cheong, "Technological modernization, the internet, and religion in Singapore "Journal of Computer-Mediated Communication, vol. 12, pp. 1122-1142. Jun. 2007.

[22] A. Baltazar, H. W. Helm, D. McBride, G. Hopkins, and J. J. Stevens, "Internet pornography use in the context of external and internal religiosity," Journal of Psychology \& Theology, vol. 38, pp. 32-40, 2010.

[23] J. N. Thomas, "Outsourcing moral authority: The internal secularization of evangelicals' anti-pornography narratives," Journal for the Scientific Study of Religion, vol.52, pp. 457-475. Sep. 2013.

[24] J. S. Carroll, L. M Padilla-Walker, L. J. Nelson, C. D. Olson, C. McNamara Barry, and S. D. Madsen, "Generation XXX: Pornography acceptance and use among emerging adults," Journal of Adolescent Research, vol. 23, pp. 6-30, Jan. 2008.

[25] P. J.Wright, R. S.Tokunaga, and S. Bae, "Pornography consumption and US adults' attitudes toward gay individuals' civil liberties, moral judgments of homosexuality, and support for same-sex marriage: Mediating and moderating factors," Communication Monographs, vol. 81,pp. 79-107, Feb. 2014.

[26] J. Grubbs, J. Exline, K Pargament, J Hook, and R. Carlisle, "Transgression as addiction: Religiosity and moral disapproval as predictors of perceived addiction to pornography," Archives of Sexual Behavior, vol. 144, pp. 125-136. Feb. 2014

[27] K. Greene, M. Krcmar, L. H. Walters, D. L. Rubin, and L. Hale," Targeting adolescent risk-taking behaviors: The contributions of egocentrism and sensation-seeking," Journal of Adolescence, vol. 23, pp. 439-461, Aug. 2000.

[28] M. Gerrard, F. X. Gibbons, A. F. Houlihan, M. L. Stock, and E. A. Pomery," A dual-process approach to health risk decision making: The prototype willingness model," Developmental Review, vol. 28, pp. $29-61$, Mar. 2008

[29] J. T. Parsons, A. W. Siegel, and J. H. Cousins, "Late adolescent risk-taking: Effects of perceived benefits and perceived risks on behavioral intentions and behavioral change," Journal of Adolescence, vol. 20, pp. 381-392, Aug. 1997.

[30] D. Eisenberg, E. Golberstein, and J. L Whitlock, "Peer effects on risky behaviors: New evidence from college roommate assignments," Journal of Health Economics, vol. 33, pp. 126-138, Jan. 2014.

[31] H. Szrek, L. Chao, S. Ramlagan, and K. Peltzer, "Predicting (un) healthy behavior: A comparison of risk-taking propensity measures" Judgment and Decision Making, vol. 7, pp. 716-727, Nov. 2012.

[32] D. Ley, N. Prause, and P. Finn, "The emperor has no clothes: A review of the 'Pornography addiction' model," Current Sexual Health Reports, vol. 1, pp. 94-105, Feb. 2014.

[33] K. S. Young, "Internet sex addiction: Risk factors, stages of development, and treatment," American Behavioral Scientist, vol. 52, pp. 21-37. Sep. 2008

[34] W. W. Chin, "The partial least squares approach to structural equation modeling," in Modern Business Research Methods, G. A. Marcoulides, Ed., Mahwah, NJ: Lawrence Erlbaum Associates, 1998, ch. 10, pp. 295-336.

[35] D. L. Delmonico and J. Miller, "The internet sex screening test: A comparison of sexual compulsives versus non-sexual compulsives," Sexual and Relationship Therapy, vol. 18, pp. 261-276, 2003.
[36] J. Grubbs, F. Volk, J. J. Exline, and K. I. Pargament, "Internet pornography use: Perceived addiction, psychological distress, and the validation of a brief measure," Journal of Sex and Marital Therapy, vol. 41, pp.83-106, Dec. 2013.

[37] J. N. Hook, J. P. Hook., D. E. Davis, E. L. Worthington, and J. K. Penberthy, "Measuring sexual addiction and compulsivity: A critical review of instruments," Journal of Sex and Marital Therapy, vol. 36, pp 227-260, 2010

[38] D. L. Delmonico. (1997). Internet sex screening test. [Online]. Available: http://www.sexhelp.com

[39] A. R. Blais and E. U. Weber, "Domain-specific risk-taking (DOSPERT) scale for adult populations," Judgment and Decision Making, vol. 1, pp. 33-47. July 2006.

[40] Y. Hanoch, J. G. Johnson, and A. Wilke, "Domain specificity in experimental measures and participant recruitment: An application to risk-taking behavior," Psychological Science, vol. 17, pp. 300-304. Apr. 2006.

[41] M. T. Buelow and A. B. Brunell, "Facets of grandiose narcissism predict involvement in health-risk behaviors," Personality and Individual Differences, vol. 69, pp. 193-198, June 2014.

[42] S. E. Krauss, "The Muslim religiosity personality inventory (MRPI) scoring manual," Institute for Social Science Studies, 2011

[43] R. Hoge, "A validated intrinsic religious motivation scale," Journal for the Scientific Study of Religion, vol.11, pp. 369-376, Dec.1972.

[44] R. L. Gorsuch and S. E. McPherson, "Intrinsic/extrinsic measurement: I/E-revised and single-item scales," Journal for the Scientific Study of Religion, vol. 28, pp. 348-354, Sep. 1989.

[45] L. R. Fabrigar and D. T. Wegener, Exploratory Factor Analysis, Oxford University Press, 2011.

[46] C. M. Ringle, S. Wende, and J. M. Becker. SmartPLS 3. Boenningstedt: SmartPLS GmbH, [Online]. Available: http://www.smartpls.com

[47] J. F. Hair, G. T. M. Hult, C. M. Ringle, and M. Sarstedt, A Primer on Partial Least Squares Structural Equation Modeling (PLS-SEM), Thousand Oaks: Sage, 2014

[48] M. Sarstedt, C. M. Ringle, J. Henseler, and J. F. Jr. Hair, "On the emancipation of PLS-SEM: A commentary on rigdon 2012," Long Range Planning, vol. 47, pp. 154-160, June. 2014.

[49] J. Henseler, C. M. Ringle, and R. R. Sinkovics, "The use of partial least squares path modeling in international marketing," Advances in International Marketing (AIM), vol. 20, pp.277-320, 2009.

[50] A. Diamantopoulos, "The error term in formative measurement models: Interpretation and modeling implications," Journal of Modelling in Management, vol.1, pp. 7-17, 2006.

[51] J. Becker, K. Klein, and M. Wetzels, "Hierarchical latent variable models in PLS-SEM: Guidelines for using reflective-formative type models," Long Range Planning, vol. 45, pp. 359-394, Oct-Dec., 2012.

[52] J. F. Hair, C. M. Ringle, and M. Sarstedt, "Editorial-partial least squares structural equation modeling: Rigorous applications, better results and higher acceptance," Long Range Planning, vol. 46, pp. 1-12, Mar. 2013

[53] W. W. Chin, "Bootstrap cross-validation indices for PLS path model assessment," in Handbook of Partial Least Squares; Concepts, Methods and Applications, V. Esposito Vinzi, W. W. Chin, J. Henseler and H. Wang eds, Verlag Berlin Heidelberg: Springer, 2010, ch. 3, pp. 83-97.

[54] J. F. Hair, C. M. Ringle, and M. Sarstedt, "PLS-SEM: Indeed a silver bullet," Journal of Marketing Theory and Practice, vol. 19, pp. 139-152, 2011

[55] J. F. Hair, M, Sarstedt, T. M Pieper, and C. M. Ringle, "The use of partial least squares structural equation modeling in strategic management research: A review of past practices and recommendations for future applications," Long Range Planning, vol. 45, pp. 320-340, Oct-Dec. 2012

[56] J. Henseler, C. M. Ringle, and M. Sarstedt, "A new criterion for assessing discriminant validity in variance-based structural equation modeling," Journal of the Academy of Marketing Science, vol. 1, pp. 115-135, Jan. 2015

[57] N. Kock, WarpPLS 2.0 User Manual, Laredo, TX: ScriptWarp Systems, 2013

[58] C. Fornell and D. F Larcker, "Evaluating structural equation models with unobservable variables and measurement error," Journal of Marketing Research, vol. 81, pp. 39-50. Feb.1981.

[59] J. Henseler et al., "Common beliefs and reality about PLS comments on rönkkö and evermann, 2013," Organizational Research Methods, vol 17 pp. 82-209, Apr, 2014.

[60] J. Cohen, Statistical Power Analysis for the Behavioral Sciences, Hillsdale, New Jersey: Lawrence Erlbaum. 1988

[61] C. M. Ringle, M. Sarstedt, and D. W. Straub, "Editor's comments: A critical look at the use of PLS-SEM in MIS quarterly," MIS Quarterly, vol. 36, pp. iii-xiv. Mar. 2012. 
Soudabeh Ghoroghi is a $\mathrm{PhD}$ candidate at University of Putra Malaysia (UPM), Malaysia. She holds a master of science degree in counseling psychology from UPM, and a bachelor of clinical psychology degree from Tehran University, Iran.

She has worked as research assistant since 2013. She also has work experience as a social worker and counselor since 1994. Her areas of research mainly include family and marital related issues, behavioral addiction and cybersex addiction.

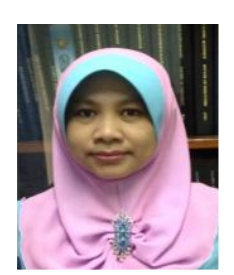

Siti Aishah Hassan has become a lecturer in the Faculty of Educational Studies, University Putra Malaysia UPM since 2006. She holds her doctoral and master degrees from the International Islamic University Malaysia in Guidance and Counseling and a bachelor of Chemistry degree from University of Missouri St. Louis, USA.

She has organized and chaired workshop and conduct trainings to educate the licensed counselors and postgraduate students on systemic theories and practices and has served as content expert in family counseling and research consultant especially on Structural Equation Modeling (SEM-AMOS) to several other agencies.

Dr. Hassan is actively involved in various research projects, especially those related to Marital, Couple and Family Counseling such as cybersex and intervention, marital conflict, adjustment and satisfaction, parental spirituality and attachment, maternal spiritual characteristics and quality time, and parent-teacher collaborative models. She has been involved in ten local and international non-profit organization and charitable works. Some of them are: a member of Malaysian Counseling Association (PERKAMA), Malaysian Psychometrics Association (MPA), American Counseling Association (ACA), Asian Psychological Association (ApsyA), and Asia Pacific Counselor Association (APECA), and a board member of Association for Marriage and Family Therapy Malaysia (AMFTM).

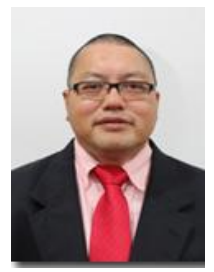

Ahmad Fauzi Mohd Ayub is an associate professor at Faculty of Educational Studies, University Putra Malaysia. He hold a $\mathrm{PhD}$ degree in educational technology from National University of Malaysia in 2008.

His major field is in information and communication technology in education and mathematics education. He has been working as matriculation teacher since 1994 and joined as lecturer in 2002. As an associate prof, he has taught many courses mainly related to information and communication technology in education, leading to the Bachelor of Education (Information Technology) degree. The courses he conducted involved both theoretical concepts and practical laboratory work. Besides that, he also taught other subjects such as testing and measurement courses and research methods. He has had hundred articles published in 6 cited journals, non-cited journals chapters of books and conferences proceeding both at international and national level. Besides being books editor and Editorial Committee for conference proceedings. 